\title{
Extraction of Bioactive Component from Herbal Anoectochilus formosanus Hayata by Microwave, Ultrasound and Lactic Fermentation
}

\author{
Le Thi Kim Ngan ${ }^{1, a}$, Nguyen Thi Ly ${ }^{1, b}$, Nguyen Thi Tham ${ }^{1, c}$, Dang Thi Kim Thuy ${ }^{2, d}$, \\ Do Dang Giap,e, Lieu My Dong, 1, ,*
}

${ }^{\text {l}}$ Faculty of Food Technology, Ho Chi Minh city University of Food Industry, Viet Nam

${ }^{2}$ Institute of Tropical Biology, Ho Chi Minh city, Viet Nam

*Corresponding author

\begin{tabular}{|c|c|}
\hline A R T I C LE I N F O & A B S T R A C T \\
\hline $\begin{array}{l}\text { Keywords: } \\
\text { Anoectochilus formosanus Hayata } \\
\text { Bioactive compounds } \\
\text { Microwave-assisted extraction } \\
\text { Ultrasound-assisted extraction } \\
\text { Fermentation } \\
\text { Lactic acid }\end{array}$ & $\begin{array}{l}\text { Anoectochilus formosanus Hayata was demonstrated to have a benefit healthy due to containing } \\
\text { active pharmaceutical ingredients. However, A. formosanus is usually processed to produce tea bags } \\
\text { which would destroy the bioactive compounds because of the processing procedure. The aim of this } \\
\text { study was to evaluate the influence of extracted methods including microwave-assisted extraction } \\
\text { (MAE), ultrasound-assisted extraction (UAE), and fermentation by Lactobacillus acidophilus } \\
\text { ATCC-4356 to extract the active pharmaceutical ingredients from A. formosanus. The extracted } \\
\text { liquid was analyzed total phenolics, total polysaccharide, and antioxidant activity. The results } \\
\text { showed that three methods have a positive effect on the extraction of bioactive compounds of A. } \\
\text { formosanus in which the fermentation showed the best result. The total phenolic content, total } \\
\text { polysaccharide content and antioxidant capacity that extracted by the fermentation method were } \\
11.762 \text { mg GAE/g; } 48.914 \text { mg GE/g, and } 1.582 \mathrm{mgVit} \mathrm{C/g} \mathrm{compare} \mathrm{to} \mathrm{MAE} \mathrm{and} \mathrm{UAE} \mathrm{which} \mathrm{were} \\
7.818 \mathrm{mg} \text { and } 8.128 \mathrm{GAE} / \mathrm{g} \text { samples; } 41.22 \text { and } 37.91 \mathrm{mg} \mathrm{GE} / \mathrm{g} \text { samples; } 1.032 \text { and } 1.163 \mathrm{mgVit} \mathrm{C} / \mathrm{g} \\
\text { respectively. The A. formosanus fermentation method by L. acidophilus promotes bioactive } \\
\text { compounds of high biological value. This study would suggest a novel use of lactic fermenting A. } \\
\text { formosanus in the production of functional foods. }\end{array}$ \\
\hline
\end{tabular}

lieudong289@gmail.com suonghatham@gmail.com dodanggiap@gmail.com https://orcid.org/0000-0002-6519-0488 https://orcid.org/0000-0003-1948-6269 https://orcid.org/0000-0001-6618-7670 $\mathbf{b} \otimes l y n g a n 06 d h t p @ g m a i l . c o m$
$\mathbf{d} \otimes$ dtkthuy@gmail.com lieudong289@gmail.com
(iD https://orcid.org/0000-0001-6010-4096 (iD) https://orcid.org/0000-0002-4212-6942 (iD) htps://orcid.org/0000-0003-2836-5290

(c) (1) (9) This work is licensed under Creative Commons Attribution 4.0 International License

\section{Introduction}

Anoectochilus formosanus Hayata and different pharmaceutical ingredients extract from A. formosanus was demonstrated that they are antioxidant (Tsenga et al., 2006), and useful for prevention and treatment of cirrhosis (Shiha et al., 2005), reducing respiratory distress syndrome of the fetus (Mayumi et al., 2004), improving the immune system, anti-tumor (Tseng et al., 2006), prevention of osteoporosis after menopause (Shih et al., 2004), treatment of neurological diseases, cardiovascular and hypertension. However, A. formosanus is usually processed to produce tea bags which would destroy the bioactive compounds because of the processing procedure. Thus, the extraction of bioactive compounds from medicinal plants is necessary to bring health benefits to consumers. Currently, methanol extraction is often used to improve the extraction efficiency. However, in food application, the extraction of bioactive compounds by methanol should be considered for use because methanol could be toxic at low concentration (200 ppm) (Clary., 2013). Therefore, researching the alternative extraction methods is necessary to obtain bioactive substances. Ultrasound-assisted extraction (UAE) and microwave-assisted extraction (MAE) are one of the potential technologies to extract compounds in herbal drug due to decreasing times and temperature of extraction and enhancing the bioactivity compounds (Vinatoru et al., 2017; Diego et al., 2016). Besides, the process of fermentation is known as a method to extract bioactive compounds effectively (Chang-Chai et al., 2011). Fermentation processing breaks down or converts the composite substrates into functional components under the action of microbial enzymes, which modified the characteristics of the product or changed the content of bioactive compounds (Ahtesham et al., 2016). Fermentation techniques also showed the increased the obtaining ability of bioactive compounds from $A$. formosanus (Chang-Chai et al., 2011). However, though these extraction methods were very promised, the study of comparison of these extracted methods including 
ultrasound-assisted extraction (UAE), microwave-assisted extraction (MAE) and fermentation was reported poorly. Therefore, the present study was conducted to evaluate the extraction efficiency of the bioactive compounds from $A$. formosanus of these methods by evaluating criteria of total phenolics, total polysaccharide, and antioxidant activity.

\section{Materials and Methods}

Anoectochilus formosanus Hayata and Microbial Strain

Biomass of A. formosanus in vitro was provided by plant cell Technology lab, Institute of Tropical Biology $\mathrm{HCM}$ city and preserved at $4^{\circ} \mathrm{C}$.

L. acidophilus ATCC 4356 was obtained from the strain collection of the Faculty of food technology of the Ho Chi Minh University of food industry. L. acidophilus was multiplied on Man Rogosa Sharpe (MRS) at $37^{\circ} \mathrm{C}$ after $22 \mathrm{~h}$ culture, biomass collection and use for the next process.

\section{Method of Extract}

Preparation of A. formosanus: A. formosanus Hayata removed roots and rotten leaves, washed and dried. $100 \mathrm{ml}$ of sterile water was added into $250 \mathrm{ml}$ the Becher containing $20 \pm 0.01 \mathrm{~g}$ of the milled sample.

Microwave treatment: MAE experiments were performed on a microwave machine (Electrolux $1250 \mathrm{~W}$ ) with microwave power $600 \mathrm{~W}, 800 \mathrm{~W}, 1000 \mathrm{~W}$; microwave time 30s, 45s, 75s, 105s, 150s, 180s, $210 \mathrm{~s}$. Then, the mixture was centrifuged at $5000 \mathrm{rpm}$ for $10 \mathrm{~min}$ and collected the supernatant fluid.

Ultrasonic treatment: UAE experiments were performed on equipment Sonics with maximum power 750 $\mathrm{W}$, frequency $20 \mathrm{kHz}$ at power $20 \%, 25 \%, 30 \%, 35 \%, 40 \%$ with ultrasonic times $5 \mathrm{~min}, 10 \mathrm{~min}, 15 \mathrm{~min}$ with a pulse ON time of. $10 \mathrm{sec}$ followed by a pulse OFF time of $10 \mathrm{sec}$. Then, the mixture was centrifuged at $5000 \mathrm{rpm}$ for $10 \mathrm{~min}$ and collected the supernatant layer.

Fermentation processing with $L$. acidophilus: The biomass of $L$. acidophilus was calibrated by spectrophotometer to reach the concentration of $L$. acidophilus of $10^{7} \mathrm{CFU} / \mathrm{ml}, 10^{8} \mathrm{CFU} / \mathrm{ml}, 10^{9} \mathrm{CFU} / \mathrm{ml}$ and fermented at $24 \mathrm{~h}, 48 \mathrm{~h}, 72 \mathrm{~h}, 96 \mathrm{~h}$. After completed fermentation process, the mixture was centrifuged at 5000 rpm for 10 min and collected the supernatant fluid.

The control samples: $100 \mathrm{ml}$ of sterile water added into the Becher $(250 \mathrm{ml})$ that contains $20 \pm 0,01 \mathrm{~g}$ of the milled sample then kept in $30 \mathrm{~min}$. After that, the mixture was centrifuged at $5000 \mathrm{rpm}$ for $10 \mathrm{~min}$ and collected the supernatant fluid.

\section{Analytical Methods}

Total phenols were determined according to the method of Li Ru-Lai et al. (2013), with slight modified. Brief, 0.1 $\mathrm{ml}$ of $A$. formosanus extract added $0.9 \mathrm{ml}$ two times distilled water and $5 \mathrm{ml}$ Folin-Ciocalteu reagent, after 3 min, added $4 \mathrm{ml} \mathrm{Na} \mathrm{CO}_{3} 7.5 \%$ (w/v). The mixture stored in dark condition to allow reaction in $30 \mathrm{~min}$. The reaction mixtures were measured at $765 \mathrm{~nm}$ absorbance. The results were calculated by $\mathrm{mg}$ as gallic acid equivalent per gram (GAE/g) that based on the calibration curve of Gallic acid (10-80 ppm).
The total polysaccharide was determined based on the method described by Dong et al. (2016), with a slight modified. Brief, $0.1 \mathrm{ml}$ of A. formosanus extract added 1.9 $\mathrm{ml}$ two times distilled water, $8 \mathrm{ml} 0.2 \%$ of anthrone reagent in concentrated sulfuric acid solution. The mixtures kept under room temperature. The reaction mixtures were measured at $630 \mathrm{~nm}$ absorbance. The result was calculated by $\mathrm{mg} \mathrm{D}$-glucose equivalent per gram $(\mathrm{GE} / \mathrm{g})$ that based on the calibration curve of D-glucose (4-50 ppm).

DPPH (1,1-diphenyl2-picrylydrazyl) antioxidant activity: Measurement of DPPH scavenging activity was determined according to Chang et al (2011) with slight modified. Briefly, $1 \mathrm{ml}$ of $A$. formosanus extract added to $1 \mathrm{ml}$ two times distilled water, $10 \mathrm{ml}$ of $0.8 \mu \mathrm{M} \mathrm{DPPH}$ methanolic solution were mixed and stored in dark condition to allow reaction at $60 \mathrm{~min}$. The reaction mixtures were measured at $517 \mathrm{~nm}$ absorbance. The result was calculated by $\mathrm{mg}$ Vitamin $\mathrm{C} / \mathrm{g}$ that based on the calibration curve of L-ascorbic acid (0-50 ppm).

\section{Statistical Analysis}

The treatments were repeated three times to calculate the average value, standard deviation. The experimental results were recorded as mean \pm standard deviation. Oneway analysis of variance was performed by ANOVA procedures LSD to verify LSD with $\alpha=0.05$ on Statgraphics $\mathrm{XV}$, calculate and show graphs at sigmaplot 11 .

\section{Results and Discussion}

Effects of Microwave-Assisted Extraction on Bioactive Components of A. formosanus Extract

The effect of the MAE method on total polyphenol content and total polysaccharide content was shown in Fig 1. These results showed that the contents of total polyphenol and total polysaccharide of the microwaveassisted sample at the optimal conditions were higher than those of the control sample $(\mathrm{P}<0.05)$. With microwave power $600 \mathrm{~W}, 800 \mathrm{~W}, 1000 \mathrm{~W}$, contents of polyphenolic and polysaccharide were highest in $180 \mathrm{~s}(7.025 \mathrm{mg}$ GAE/g sample, $40.114 \mathrm{mg} \mathrm{GA} / \mathrm{g}$ sample), $75 \mathrm{~s}$ (7.818 mg GAE/g sample, $41.220 \mathrm{mg} \mathrm{GE} / \mathrm{g}$ sample) and $75 \mathrm{~s}(7.338 \mathrm{mg}$ GAE/g sample, $37.220 \mathrm{mg}$ GE/g sample) respectively.

These results indicated that the polyphenolic and polysaccharide contents also increased similarly in the same point in time in the experiment. Time and microwave power of the MAE method effected significantly on the recovery of the phytochemical components (Fig 1). The high of electric-field energy at the high power have formed the rotation of dipole, leading to the friction among molecules, and the high pressure which breaks the biological matrix and release the biological components (Ali et al., 2007). At the low microwave power leading to the microwave energy was low, so the prolonging of microwave time was necessary to reach the boiling point of water. The disruption of friction into cell walls and the increase of microwave time have enhanced the penetration of extracting solvent through the matrix facilitating the obtainment of the target compounds (Vinatoru et al., 2017). On the other hand, in the same of microwave power, if the extraction time were much longer, the obtained component contents increased more rapidly. Nevertheless, the high of microwave power and the long-time of extraction 
decreased the compound contents rapidly. For 210 s of irradiation time, the content of polyphenol and polysaccharide reduced $7.2 \%, 48.67 \%, 58.86 \%$ and $10.67 \%, 22.45 \%, 34.02 \%$ in $600 \mathrm{~W}, 800 \mathrm{~W}, 1000 \mathrm{~W}$ respectively. The high of microwave power, as well as the long-time extraction, has increased the extracted temperature leading to decreasing the obtained compounds.

DPPH radical scavenging activity of MAE sample increased higher than that of the control sample $(\mathrm{P}<0.05)$ and the highest antioxidant activity was achieved at the time of $105,75,45$ seconds corresponding to the microwave power of $600 \mathrm{~W}, 800 \mathrm{~W}, 1000 \mathrm{~W}$ (Fig. 2). These results corresponded with the results of the content of total phenolics and polysaccharide (Fig 1), this is because they are the compounds with radical-scavenging activity (WonWoo et al., 2013). The DPPH radical scavenging activity was decreased strongly at the different microwave power when prolonging the extraction time up to 210 s. The antioxidant activities of the heat-sensitive compounds decreased with the prolonging of microwave time. These results showed that the optimal conditions to obtain the highest recovery were $75 \mathrm{~s}$ at $800 \mathrm{~W}$ (Fig 1,2).

\section{Effects of Ultrasonic Treatment on Bioactive} Components of A. formosanus

The ultrasonic-assisted sample obtained the higher polyphenol and polysaccharide contents than that of the control samples $(\mathrm{P}<0.05)$ (Fig.3). Ultrasonic time affected significantly the content of polyphenol and polysaccharide. In the same ultrasonic time, the content of total polyphenol and polysaccharide increased with the ultrasonic power from $20 \%$ to $25 \%$, the highest content at $25 \%$ power but decreased at high ultrasonic power $30 \%, 35 \%, 40 \%$. In the $25 \%$ of ultrasonic power, the content of polyphenol and polysaccharide increased with the extension of the radiation time from 5 to 10 minutes, which demonstrated that the extension of ultrasonic time led to the increase of the recovery rate. Ultrasonic method is widely used to extract various substances from a plant by creating microscopic bubbles that believed in to create high-shear gradients by causing micro-streaming which disrupts the cell walls leading to accelerates the penetration of solvent into cells and the release of components from cells into the solvent, and simultaneously significantly enhances the mass transfer rate (Yuting et al., 2013).

In the present study indicated that the antioxidant activity in $5 \mathrm{~min}, 10 \mathrm{~min}, 15 \mathrm{~min}$ was achieved the highest at the ultrasonic power of $35 \% ; 25 \%$ and $25 \%$ respectively and when increasing the ultrasonic power up to $35 \%, 40 \%$, the free-radical scavenging activity decreased gradually. The increases of the antioxidant activity were due to the content of polyphenol and polysaccharide was high achieved which contributed to the antioxidant activity (WonWoo et al., 2013). At a power sufficiently high, water molecules can be broken generating highly reactive free radicals $\left(\mathrm{H}_{2} \mathrm{O} \rightarrow \mathrm{H}^{+}+\mathrm{OH}^{-}\right)$that may react with and modify other molecules (antioxidant) (Ana Cristina et al., 2010). In the present study showed that the ultrasonic treatment with the power of $25 \%$ in $15 \mathrm{~min}$, the effects of the recovery of bioactive substances was the highest (Fig 3, 4).

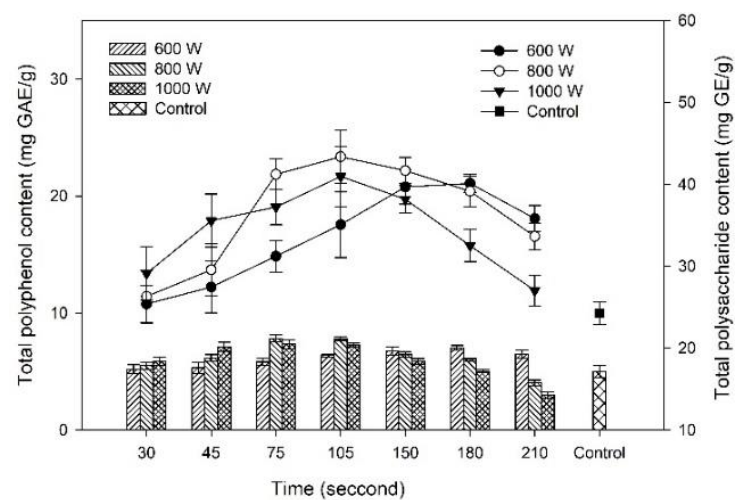

Fig 1 Effects of microwave treatment on content of total phenolics, total polysaccharide

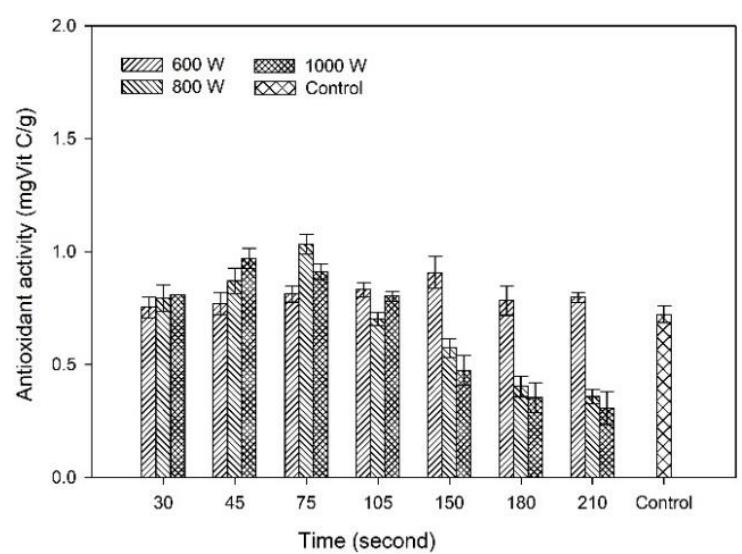

Fig 2 Effects of microwave treatment on antioxidant activity

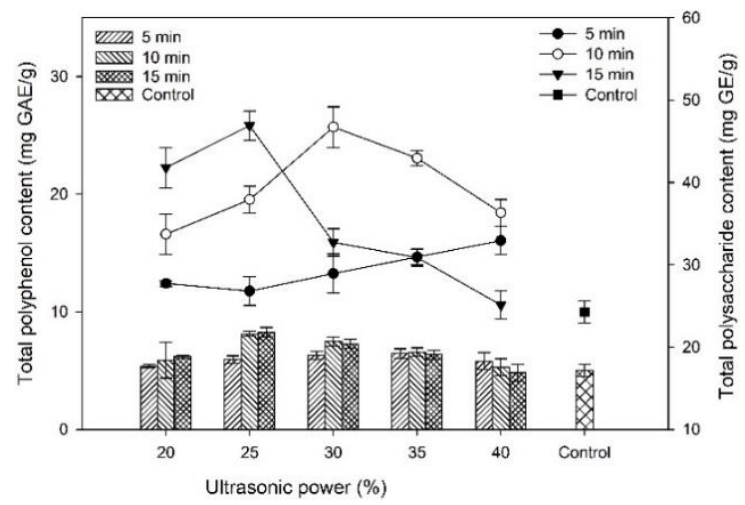

Fig 3 Effects of ultrasonic-treatment on total phenolics, total polysaccharide

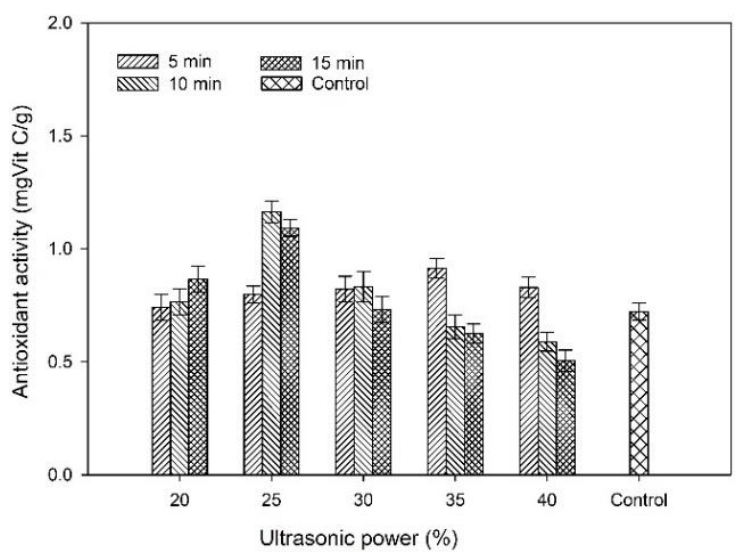

Fig 4 Effects of ultrasonic treatment on content of antioxidant activity 
Effects of Fermentation on Bioactive Substance of A. formosanus.

The effects of fermentation process by Lactobacillus acidophilus on the content of total phenolics and polysaccharide were shown in Fig. 5.

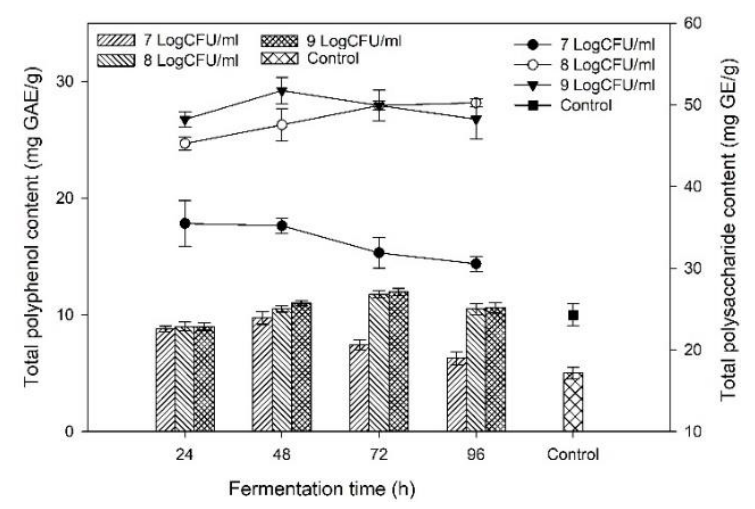

Fig 5 Effects of fermentation on content of total phenolics, total polysaccharide

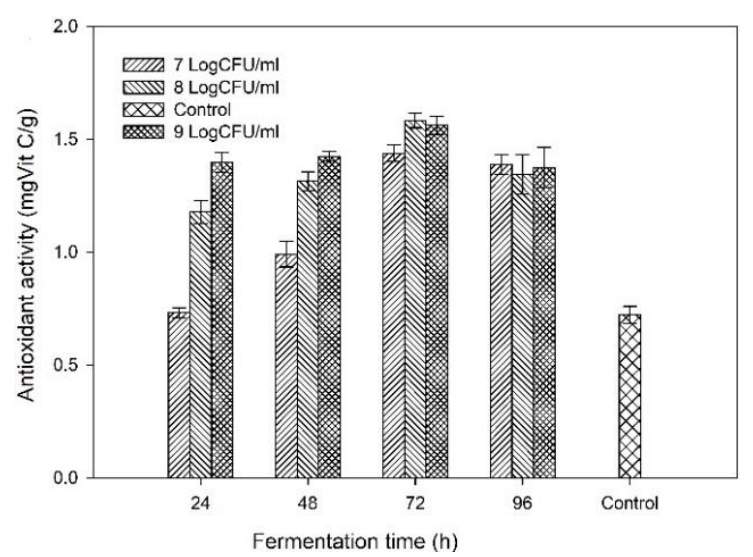

Fig 6 Effects of fermentation on antioxidant activity

These results showed that the obtained total phenolics was higher compared to the unfermented sample $(p<0.05)$. The content of polyphenol achieved from the concentration of $10^{7} \mathrm{CFU} / \mathrm{ml}, 10^{8} \mathrm{CFU} / \mathrm{ml}, 10^{9} \mathrm{CFU} / \mathrm{ml}$ was higher 1.9 times (9.747 mg GAE/g sample), 2.3 times $(11.762 \mathrm{mg}$ GAE/g sample) and 2.4 times (11.962 mg GAE/g sample) compared to the unfermented sample, respectively. In the fermentation processing, Lactobacillus acidophilus metabolized or convert the crude matrix into biological components. The change of the polyphenol-protein, polyphenol-lipid bonds in the fermented process led to release free phenol, reduce the content of the associated phenol (Li-Ru et al., 2013). However, when the time of fermentation kept longer, the polysaccharide content decreased gradually (Fig, 5). This might be explained that lactic bacteria released the active enzyme such as amylase, $\beta$ - glucosidase which can transfer polysaccharide into monosaccharide and used them to produce ATP for the biosynthesis of lactic acid and the last products (Ratchadaporn et al., 2018). The content of polysaccharide at the concentration of $10^{9} \mathrm{CFU} / \mathrm{ml}(48.207 \mathrm{mg} \mathrm{GE} / \mathrm{g}$ sample) obtained higher than that of $10^{7} \mathrm{CFU} / \mathrm{ml}(35.466$ $\mathrm{mg}$ GE/g sample) and $10^{8} \mathrm{CFU} / \mathrm{ml}$ (45.257 $\mathrm{mg} \mathrm{GE} / \mathrm{g}$ sample) after $24 \mathrm{~h}$ for fermentation. The total polysaccharide was tended to decrease gradually after $48 \mathrm{~h}$, $72 \mathrm{~h}$, and $72 \mathrm{~h}$ fermentation at the concentration of $10^{7}$ $\mathrm{CFU} / \mathrm{ml}, 10^{8} \mathrm{CFU} / \mathrm{ml}$, and $10^{9} \mathrm{CFU} / \mathrm{ml}$ respectively (Fig. 5). This showed that the increase of the concentration of $L$. acidophilus enhanced the catalytic ability to the biochemical reaction which released much more compounds but consumed a lot of energies in their growth process.

The results for the effects of the fermentation by $L$. acidophilus on the antioxidant activity displayed in Fig. 6 which showed that the highest antioxidant capacity of samples fermented at the concentration of $10^{8} \mathrm{CFU} / \mathrm{ml}$ in $72 \mathrm{~h}$. These results corresponded with the content of polyphenol and polysaccharide achieved. These results could be explained by the content of bioactive compounds that modified during fermentation through the metabolic activity of microbes. Especially, lactic acid bacteria have an enzyme which can produce the highly antioxidant such as hydroxytyrosol, pyrogallol, 4-vinyl phenol, 4-vinyl guaiacol. The antioxidant activity of the flavonoid aglycone is 10 to 12 times higher compared to flavonoid glucosides (Sheng-Yang et al., 2002). L. acidophilus contained $\beta$-glucosidase which can cleave flavonoid glucoside into aglycone (Axelle et al.,2017). This enhanced the antioxidant capacity (Fig. 6). According to Chang-Chai et al., (2011), A. formosanus is processed to produce tea bags for consumption in Taiwan, however, the processing procedure possibly destroys the functional compounds, which reduces the aroma and flavor of $A$. formosanus herbal tea.

Table 1 Comparison of the different extraction methods

\begin{tabular}{l|ccc}
\hline $\begin{array}{c}\text { Treatment } \\
\text { methods }\end{array}$ & $\begin{array}{c}\text { Total polyphenol content } \\
(\mathrm{mg} \mathrm{GAE} / \mathrm{g})\end{array}$ & $\begin{array}{c}\text { Total polysaccharide content } \\
(\mathrm{mg} \mathrm{GE} / \mathrm{g})\end{array}$ & $\begin{array}{c}\text { Antioxidant activity } \\
(\mathrm{mg} \mathrm{VitC} / \mathrm{g})\end{array}$ \\
\hline Control & $(5.010 \pm 0.5)^{\mathrm{a}}$ & $(24.266 \pm 0.930)^{\mathrm{a}}$ & $(0,722 \pm 0,037)^{\mathrm{a}}$ \\
Microwave & $(7.818 \pm 0.305)^{\mathrm{b}}$ & $(41.220 \pm 1.86)^{\mathrm{b}}$ & $(1,032 \pm 0,043)^{\mathrm{b}}$ \\
Ultrasonic & $(8.128 \pm 0.216)^{\mathrm{b}}$ & $(37.910 \pm 1.61)^{\mathrm{c}}$ & $(1,163 \pm 0,047)^{\mathrm{b}}$ \\
Fermentation & $(11.762 \pm 0.311)^{\mathrm{c}}$ & $(49.914 \pm 3.46)^{\mathrm{d}}$ & $(1,582 \pm 0,032)^{\mathrm{c}}$ \\
\hline
\end{tabular}

${ }_{\text {abc }}$ Representing significant differences $(\mathrm{P}<0.05)$ in each experiment

Research on the effect of MAE, UAE, and fermentation methods on the recovery of the bioactive compounds was reported in the previous studies (Ana Álvarez et al., 2017; Vinatoru et al., 2017; Chang-Chai et al., 2011). However, the evaluation of the effects among these methods had not yet been published sufficiently. The results in this study showed that all microwave-assisted, ultrasonic treatment, fermentation methods effected positively on exploiting the bioactive components from A. formosanus. The fermented processing from A. formosanus showed that the effects of the recovery rate of biological compounds were higher compared to two other methods (Table 1). Microwave and ultrasonic were the extract process with physical affectations, different from them, the fermentation not only 
enhanced extract capacity of the functional components from A. formosanus but also create the highly bioactive substances due to the metabolic activity of microbes. In the next study, it suggests evaluating the effects of three combined methods, making a simulation to find the optimal conditions for the highest recovery rate of bioactive components.

\section{Conclusion}

The results of this study indicated that all microwaveassisted, ultrasonic-assisted, and fermentation methods enhanced the ability of exploitation of biological substances from $A$. formosanus. The maximum bioactive components recovery from $A$. formosanus including the microwave power was $800 \mathrm{~W}$ in $75 \mathrm{~s}$, ultrasonic treatment at $25 \%$ of power in $10 \mathrm{~min}$ and fermentation with Lactobacillus acidophilus at the concentration of 108 $\mathrm{CFU} / \mathrm{ml}$ in $72 \mathrm{~h}$. In which, fermentation achieved the highest bioactive components recovery compared to the other methods, simultaneously, enhanced the biological activity of those compounds. A. formosanus fermented by Lactobacillus acidophilus at the concentration of $10^{8}$ $\mathrm{CFU} / \mathrm{ml}$ in $72 \mathrm{~h}$ obtained the highest total polyphenol and polysaccharide content which are $11.762 \mathrm{mg}$ GAE/g sample and $48.914 \mathrm{mg} \mathrm{GE} / \mathrm{g}$ respectively. The antioxidative ability of fermented A. formosanus was higher 3 folds than that of the control. This study demonstrated that the fermentation by L. acidophilus is the potential technology which can replace other methods to obtain the bioactive compounds from A. formosanus and increase pharmacological properties of those compounds

\section{Acknowledgments}

The authors gratefully acknowledge Ho Chi Minh City University of Food Industry for the financial support

\section{References}

Ahtesham H, Bose S, Wang JH, Yadav MK, Mahajan GB, Kim H. 2016. Fermentation, a feasible strategy for enhancing bioactivity of herbal medicines. Food Research International 81: pp. 1-16. DOI: 10.1016/j.foodres.2015.12.026

Ana A, Poejo J, Matias AA, Duarte CM, Cocero MJ, Mato RB, 2017. Microwave pretreatment to improve extraction efficiency and polyphenol extract richness from grape pomace. Effect on antioxidant bioactivity. Food and Bioproducts Processing 106: 162-170. DOI: 10.1016/j.fbp.2017.09.007

Ana SC, Villamiel M. 2010. Effect of ultrasound on the technological properties and bioactivity of food: a review. Trends in Food Science \& Technology 21(7): pp. 323-331. DOI: 10.1016/j.tifs.2010.04.003

Ali L, Palma M, Brigui J, Barroso CG. 2007. Investigation on phenolic compounds stability during microwave-assisted extraction. Journal of Chromatography A 1140(1): pp. 29-34.
Axelle SM, Remize F, Poucheret P. 2017. Fruits and vegetables, as a source of nutritional compounds and phytochemicals: Changes in bioactive compounds during lactic fermentation. Food Research International 104: pp. 86-99. DOI: 10.1016/j.foodres.2017.09.031

Chang-chai NG, Wang CY, Wang YP, Tzeng WS, Shyu YT. 2011. Lactic acid bacterial fermentation on the production of functional antioxidant herbal Anoectochilus formosanus Hayata. Journal of Bioscience and Bioengineering 111 (03): pp. 289-293. DOI: 10.1016/j.jbiosc.2010.11.011

Clary JJ. 2013. The toxicology of methanol. John Wiley \& Sons.

Diego R, Venturini ME, Oria R, Arias E. 2016. Inhibitory effect of microwaved thinned nectarine extracts on polyphenol oxidase activity. Food Chemistry 197: pp. 603-610. DOI: 10.1016/j.foodchem.2015.11.009

Dong ZY, Wan Y, Xu JY, Wu GH, Li L, Yao XH. 2016. Ultrasound extraction of polysaccharides from mulberry leaves and their effect on enhancing antioxidant activity. Carbohydrate Polymers 137: pp. 473-479. DOI: 10.1016/j.carbpol.2015.11.016

Li-Ru L, Hsieh SC, Huang HY, Chou CC. 2013. Effect of lactic fermentation on the total phenolic, saponin and phytic acid contents as well as anti-colon cancer cell proliferation activity of soymilk. Journal of Bioscience and Bioengineering 115 (5): pp. 552-556. DOI: 10.1016/j.jbiosc.2012.11.022

Mayumi I, Yamaguchi K, Nishimura T, Yazawa K. 2004. Effects of Anoectochilus formosanus on Endurance Capacity in Mice. Journal of Nutritional Science and Vitaminology 51(1), pp. 40-44. DOI: $10.3177 /$ jnsv.51.40

Ratchadaporn K, Kerdchoechuen O, Laohakunjit N, Somboonpanyakul P. 2018. B vitamins and prebiotic fructooligosaccharides of cashew apple fermented with probiotic strains Lactobacillus spp., Leuconostoc mesenteroides and Bifidobacterium longum. Process $\begin{array}{llll}\text { Biochemistry 70: pp. } & 9-19 . & \text { DOI: }\end{array}$ 10.1016/j.procbio.2018.04.009

Sheng-Yang W, Kuo YH, Chang HN, Kang PL, Tsay HS, Lin KF, Yang NS, Shyur LF. 2002. Profiling and Characterization Antioxidant Activities in Anoectochilus formosanus Hayata. Food Chemistry 50: pp. 1859-1865. DOI: 10.1021/jf0113575

Shih CC, Wu YW, Lin WC. 2005. Aqueous extract of Anoectochilus formosanus attenuate hepatic fibrosis induced by carbon tetrachloride in rats. Phytomedicine 12(6-7): pp. 453-460. DOI: 10.1016/j.phymed.2004.02.008

Tseng CC, Shang HF, Wang LF, Su B, Hsu CC, Kao HY, Cheng KT. 2006. Antitumor and immunostimulating effects of Anoectochilus formosanus Hayata. Phytomedicine 13(5): pp. 366-370. DOI: 10.1016/j.phymed.2004.01.016

Vinatoru M, Mason TJ, Calinescu I. 2017. Ultrasonically Assisted Extraction (UAE) and Microwave Assisted Extraction (MAE) of Functional Compounds from Plant Materials. Trac Trends in Analytical Chemistry 97: pp. 159178. DOI: 10.1016/j.trac.2017.09.002

WonWoo L, Ahn G, Lee BJ, Wijesinghe WAJP, Kim D, Yang H, Kim YM, Park SJ, Jee Y, Jeon YJ. 2013. Radio-protective effect of polysaccharides isolated from Lactobacillus brevis fermented Ecklonia cava. International Journal of Biological Macromolecules 52: pp. 260-266. DOI: 10.1016/ j.ijbiomac.2012.10.004

Yuting T, Xu Z, Zheng B, Lo YM. 2013. Optimization of ultrasonic- assisted extration of pomegranate (Punica granatum L.) seed oil. Ultrasonics Sonochemistry 20. Pp. 202-208. DOI: 10.1016/j.ultsonch.2012.07.010 